\title{
Use of the IPAQ questionnaire in the form of a mobile application in monitoring physical activity of patients with cardiovascular diseases
}

\author{
Tomasz Saran ${ }^{1, A-F}$, Jakub Owoc ${ }^{2, D, F}$, Iwona Bojar ${ }^{3, D, F}$ \\ ${ }^{1}$ Department of General and NeuroRehabilitation, Institute of Rural Health, Lublin, Poland \\ ${ }^{2}$ College of Public Health, Zielona Góra, Poland \\ ${ }^{3}$ Department for Woman Health, Institute of Rural Health in Lublin, Poland \\ A - Research concept and design, B - Collection and/or assembly of data, C - Data analysis and interpretation, \\ $D$ - Writing the article, E - Critical revision of the article, F- Final approval of article
} Saran T, Owoc A, Bojar I. Use of the IPAQ questionnaire in the form of a mobile application in monitoring physical activity of patients with
cardiovascular diseases. Ann Agric Environ Med. 2018; 25(3): 395-402. doi: $10.26444 /$ aaem/75704

\begin{abstract}
I Abstract
Introduction. Systematic, dynamic physical effort brings about tremendous health benefits, not only in young individuals, but as a form of primary prevention, and primarily as secondary prevention of cardiovascular system diseases.

Materials and method. The research project was conducted in the Rehabilitation Centre at the Witold Chodźko Institute of Rural Health (IMW) in Lublin, Poland, and covered a group of 927 ambulatory patients. From among the study group, two subgroups were distinguished (Groups 1 and 2). Selection of patients was targeted, based on the criterion of the existing diagnosis of cardiovascular diseases (Group 1; N=53), and the lack of these diseases (Group 2; $N=53$ ). The daily level of physical activity was assessed using the monitoring application (Instrument for Activity Measurement IMW) - using a short version of the International Physical Activity Questionnaire (IPAQ), and alternatively analyzing the data from a smartphone accelerometer.

Results.The total level of weekly physical activity in Group 1 was $4532.88 \pm 3611.6$ MET-min/week, and was considerably higher, compared to the control group (3142.58 $\pm 2536.9 \mathrm{MET}-\mathrm{min} /$ week). Also, the values of weekly caloric cost of physical activity (KAF kcalxweek ${ }^{-1}$ ) showed higher values (6935.77 \pm 5957.4$)$, compared to the control group (4274 \pm 3344.9$)$. The group of cardiologic patients (Group 1) showed a higher level of activity, especially within the range of effort on an intensive level, and low level - going for walks, walking(MET1, MET3), which was also translated into the caloric cost of these levels of physical activity (KAF1, KAF3).

Conclusions. The results of the study indicated a significantly higher level of physical activity in the group of patients with concomitant cardiovascular diseases, compared to the control group. The overestimation of the level of physical activity perceived by patients seems to be an important problem, especially in the control group.
\end{abstract}

\section{Key words}

IPAQ, cardiovascular diseases, motor activity, telerehabilitation

\section{INTRODUCTION}

The development of civilisation and technical progress contribute to the sedentary life style among millions of people worldwide, which is reflected in their state of health. The report by the World Health Organization (WHO) indicates that patients with concomitant diseases, such as diabetes, ischemic heart disease, chronic obstructive lung disease, and other chronic diseases, constitute $77 \%$ of patients in Europe, and are the cause of as many as $86 \%$ of deaths [1].

A review of the relevant literature allows only the unequivocal emphasis that systematic dynamic physical effort brings about tremendous health benefits, not only in young persons, but as primary prevention of many diseases, and primarily as secondary prevention of cardiovascular system diseases. It is an important element of leisure of 'contemporary man' burdened with chronic civilisation stress and static effort [2].

Address for correspondence: Tomasz Saran, Witold Chodźko Institute of Rural Health, Lublin, Poland, Jaczewskiego 2, 20-090 Lublin, Poland e-mail: saran.tomasz@imw.lublin.pl

Received: 12.05.2017; accepted: 05.07.2017; first published:30.08.2017
The results of many studies prove that an increased level of physical activity exerts a great effect on the morphological, physiological and biochemical changes affecting the normal state of health of each individual. Systematic physical effort has an effect on the functional regulation of the cardiovascular system, modifies haemodynamics of morphological changes of blood vessels and the heart muscle, and also changes in its metabolism. Nevertheless, one of the most important benefits of undertaking this effort is the reduction of the risk of development of cardiovascular system diseases (CVD) [3]. In addition, it improves the functional balance between the coagulation system and fibrinolysis, decreases the level of systolic and diastolic blood pressure, results in an improvement of cardiovascular functions, exerts a beneficial effect on the body mass index, counteracting the development of overweight and obesity $[4,5]$. Physical training affects also the vessels relaxation function of the epithelium, increases the sensitivity of tissues to insulin, thus decreasing the risk of contracting diabetes [6].

Medical literature not only unequivocally emphasizes the beneficial effect of physical activity on the reduction of the risk of cardiovascular system diseases [5, 7-10], but also on the decrease in the number of deaths, both 
premature and total [7]. Therapeutic management in which a systematic physical effort plays a superior role may result in a significant decrease in the mortality rate in the group of patients who had undergone cardiovascular events, especially those with a history of past myocardial infarction. This has been confirmed by two 3 -year observation metaanalyses of 21 randomized clinical trials which covered a group of more than 4,000 patients who had undergone myocardial infarction, which showed a $25 \%$ reduction in mortality rate in the group subjected to the programme of therapeutic rehabilitation [11]. Also, metaanalysis of nine clinical trials ExTraMATCH, which included a group of 801 patients with heart failure, confirmed a decrease by $35 \%$ of mortality rate in a distant two-year observation [12].

Favourable economic balance in the form of reduction in the costs of health care has become a strong incentive for the development of telemedical systems. One of the first branches in their development is telerehabilitation, applied in cardiology, orthopaedics, neurology, or psychiatry [13]. In the presented study, for assessment of the level of physical activity, an application was adopted which used the potential of the contemporary mobile network to which almost everyone has access. A very important element of rehabilitation of patients with past cardiovascular events is the sustaining of the achieved results by the individual patient. Therapeutic management should cover not only a systematically undertaken physical activity, but primarily, widely-understood primary and secondary prevention, patient education aimed mainly at the implementation of physical activity into daily life, especially by young persons, as the primary prevention of many chronic diseases [14].

\section{OBJECTIVE}

The primary objective of the statistical analysis was an assessment of the weekly level of physical activity in a group of patients with concomitant cardiovascular diseases, compared to the control group consisting of patients using mobile application, processing the data from a smartphone accelerometer.

\section{MATERIALS AND METHOD}

Study design. The research project was conducted in the Rehabilitation Centre at the Witold Chodźko Institute of Rural Health in Lublin, Poland, and covered a group of 927 ambulatory patients. From among the study group, based on the patient's medical history at admission to the rehabilitation programme, two subgroups were distinguished (Groups 1 and 2). Selection of patients into individual groups was targeted, based on the criterion of concomitant cardiovascular system diseases and chronic diseases. In Group 1 (53 patients), chronic heart failure (I-II NYHA class) was reported in $42 \%$ of patients, arterial hypertension in $76 \%$, and past history of coronary event, infarction or instable for of angina pectoris in 23\%. The duration of the period which had elapsed since the occurrence of myocardial infarction was within the range of more than one year. Into Group 2, the same number of patients were qualified, without concomitant diseases, who constituted a control group for comparison with Group 1. The control group was selected at random from among patients who did not report cardiovascular diseases in medical history taking.

Assessment of the level of physical activity was obtained using a monitoring application (Instrument for Measurement of Activity IMW) which, in practice, uses the potential of contemporary smartphones. The application was created in order to constantly monitor the level of physical activity of patients discharged from the Rehabilitation Centre at the Institute of Rural Health. Volunteers were engaged by physiotherapists, and also had the opportunity to take advantage of the so-called 'feedback' from a group of specialists, including doctors and physiotherapists. Physiotherapists had the opportunity to individually follow their patients at home by means of web software. All volunteers from the Rehabilitation Department received explanations and answers to questions about the telemonitoring system. Consent for medical monitoring and scientific evaluation of anonymous data was expressed by smartphone interface.

The application contains an original algorithm of data processing from the accelerometer, as well as the short version of the International Physical Activity Questionnaire IPAQ - 7 items. The processing of data from the smartphone accelerometer of each patient from the aspect of evaluation of the level of physical activity takes place using algorithms and filters for processing the values of gravitational acceleration vectors, and by means of two types of individual calibration. The first is a static calibration, which determines the values of gravitational acceleration measured on the accelerometer by placing the mobile phone flat and pressing the measuring key for three seconds $\left(g=\operatorname{sqrt}\left(\mathrm{x}^{2}+\mathrm{y}^{2}+\mathrm{z}^{2}\right)\right.$, as a result of the mean value obtained from measurements for three seconds $(\mathrm{x}, \mathrm{y}, \mathrm{z} \rightarrow$ instantaneous acceleration components from accelerometer). Elimination of the differences in sensitivity of accelerometers of various types of smartphones was obtained by dynamic calibration, by pressing the key, placing the smartphone in the place in which it is carried, and subsequently starting marching over a flat surface for one minute, until the moment of obtaining the signal of ending calibration (dynamic correction = 3.3/amount MET-min for $1 \mathrm{~min}$ march).

The application allows daily monitoring of physical activity from 08:00 - 11:00, and by the diagram of a 'filling heart', as well as by text messages, enables the motivation of patients to increase the level of physical activity if it is too low. Full access to the data by physicians and physiotherapists is possible due to data collection (once a day), which are sent to the Institute's server and then presented in collective graphs (Fig. 1).

The international questionnaire IPAQ used in the application enabled the collection of information concerning the assessment of the level of physical activity within the last 7 days. The level of intensity of physical effort was evaluated by the metabolic equivalent - MET. For various levels of physical activity, the values were adopted, respectively: 3.3 MET for low frequency efforts (walks) - (MET3), MET4for moderate level (MET2), and for intensive effort 8 MET (MET1). The total weekly level of physical activity (MET-min/week) was obtained by multiplying the number of days and duration of effort by the respective MET value ascribed to individual level of physical, and subsequently, summing-up of the results obtained which, according to the recommendations by the World Health Organization (WHO), allowed the qualification of patients into three different categories of physical activity [15]: 

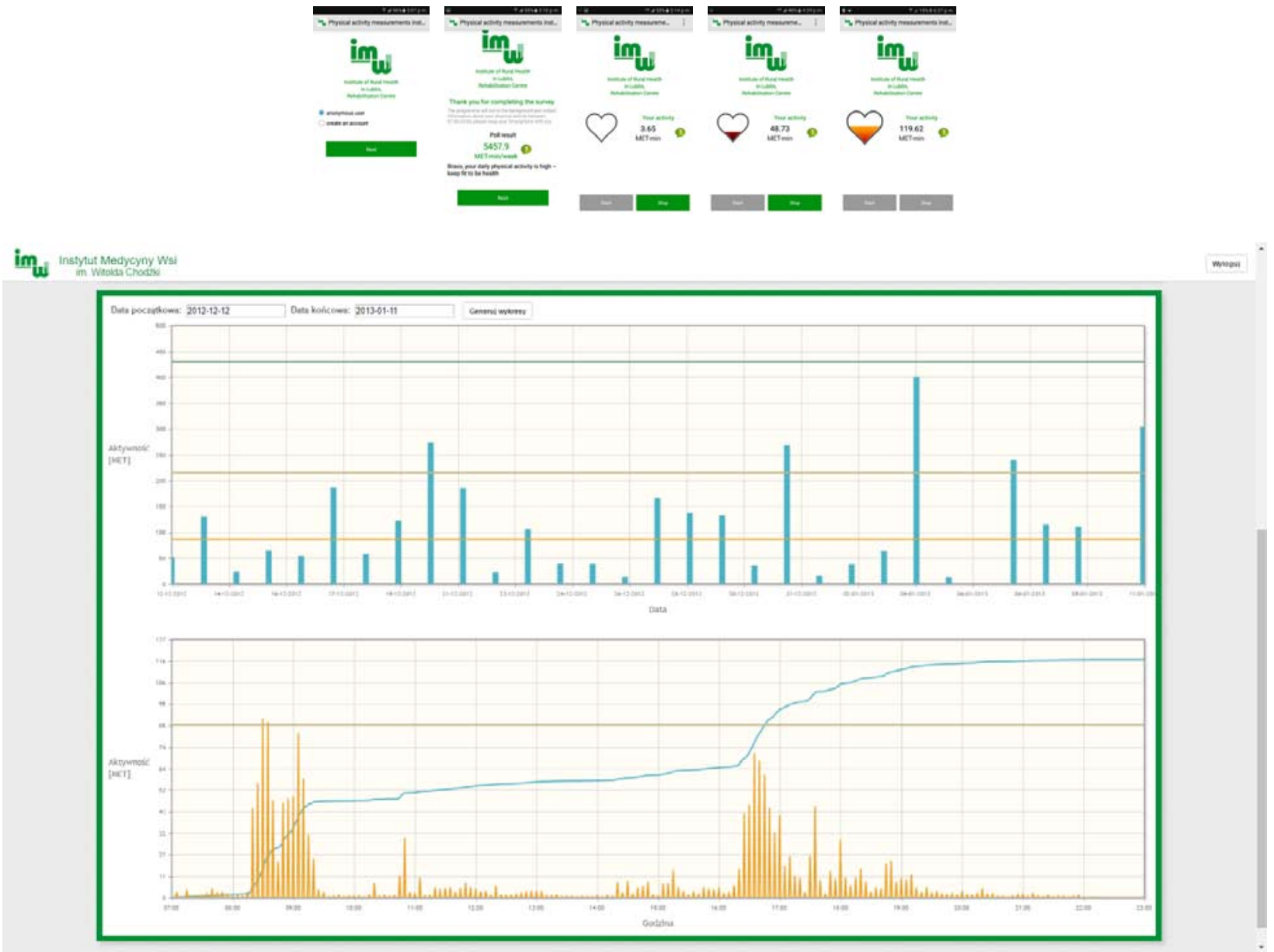

Figure 1. Above: measuring application (application interface). Below: sample reading of physical activity of one user (web data-showing interface)

- Insufficient - $\downarrow 600 \mathrm{MET}$-min/week.

- Sufficient - 600-1500 MET-min/week, or a combination of intensive/moderate efforts, at least $600 \mathrm{MET}$-min/week: $\checkmark$ 3days/or $\uparrow$ intensive physical effort (not less than 20 $\mathrm{min} /$ daily);

$\checkmark 5$ days/or $\uparrow$ moderate physical effort/or walks (not less than $30 \mathrm{~min} /$ daily).

- High - $\uparrow 1,500 \mathrm{MET}-\mathrm{min} /$ week:

$\checkmark 3$ days of intensive physical effort (not less than $30 \mathrm{~min} /$ daily);

$\checkmark$ daily physical activity on moderate/intensive level exceeding 3,000 MET-min/week (at least 30 minutes) [16].

Data analysis also included weekly caloric cost (KAF kcalxweek $\left.{ }^{-1}\right)$ separately for individual levels of physical activity (KAF1- intensive efforts, KAF2- moderate efforts, KAF3- low frequency efforts, e.g. walks), which is the best reflection of weekly energy expenditure (MET-min/week) $[17,18]$.

\section{$\mathrm{KAF}=\mathrm{TAF} \times 60 \mathrm{~min}^{-1} \times \mathrm{MC}$}

TAF - weekly volume of physical activity [MET-min/week] MC - body weight $[\mathrm{kg}]$

The criteria for evaluation of the level of physical activity used in the study consider contemporary health recommendations, the basis of which is the regularity of undertaking this activity, especially by persons with concomitant cardiovascular diseases, but primarily in the prevention of chronic diseases [19].

Considering the inconsistency of data with normal distribution and a considerable number of outlying elements for the analysis of the examined parameters, non-parametric statistics were used. Statistical data were elaborated using the software Statistica 12.0. For analysis of data, basic descriptive statistics, sign test, Mann-Whitney U test, and Spearman rank correlation were used.

Study group. A group of 106 patients were qualified for statistical analysis and divided into two subgroups with 53 patients in each group. In Group 1, the mean age of patients was $35.77 \pm 9.27$, with the largest number being males (92\%); additionally, the largest part of this group were occupationally active (74\%). Mean value of weight-to-height ratio was $27.31 \pm 5.13 \mathrm{~kg} / \mathrm{m}^{2}$. Considering the BMI, $22 \%$ of patients showed a normal body weight, while $40 \%$ of patients in this group were overweight or obese (38\%) (Fig.1; Tab.1).

Group 2 - control group were 53 patients, mean age $48.77 \pm 14.05$, occupationally-active ( $81 \%$ ), with the prevalence of males $(74 \%)$. The mean BMI values were slightly higher, compared to Group $1\left(28.80 \pm 5.63 \mathrm{~kg} / \mathrm{m}^{2}\right)$. In this group, the number of persons with normal body weight was considerably higher, compared to Group 1 (36\%), the largest number of patients in this group were overweight (43\%), with a lower percentage of those who were obese (21\%) (Fig.1; Tab.1). 


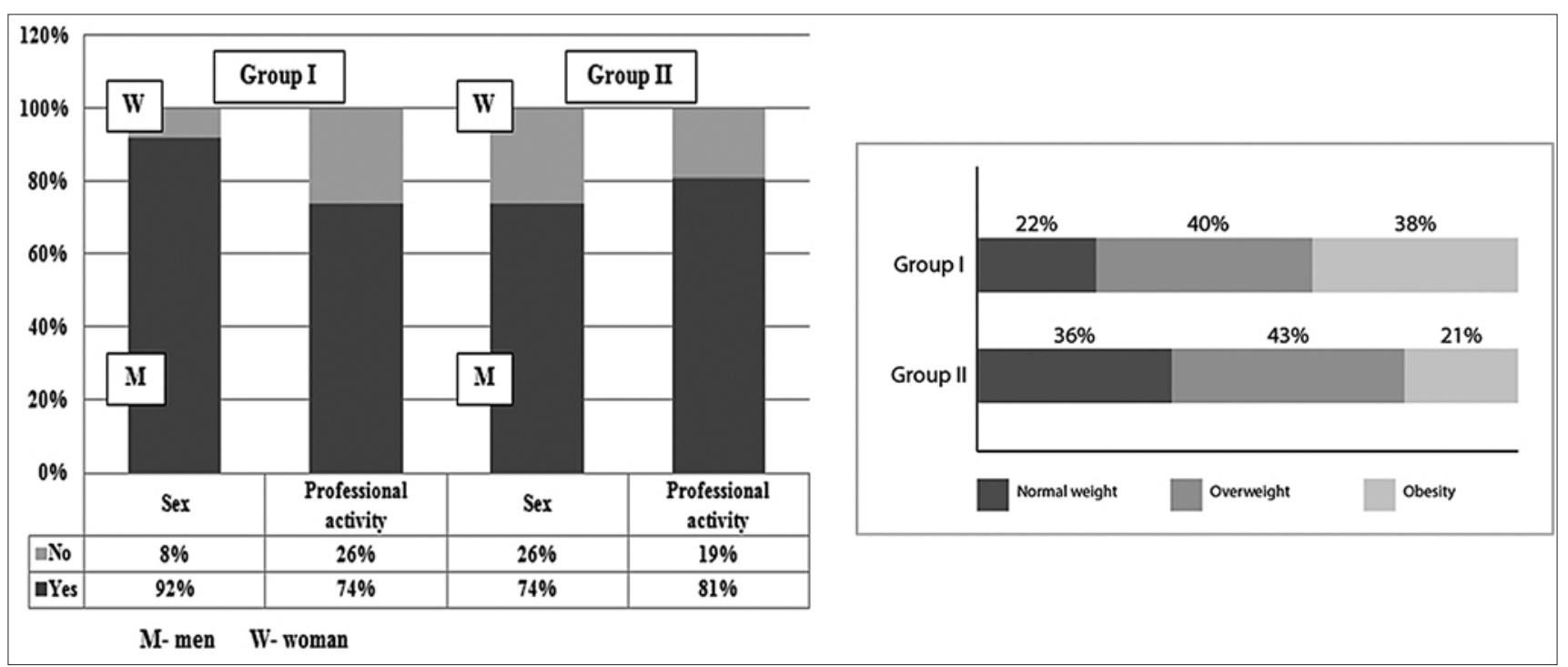

Figure 2. Characteristics of the examined group

Table 1. Characteristics of Groups 1 and 2

\begin{tabular}{lcccccc}
\hline Variable & $N$ & Mean & Median & Minimum & Maximum & $( \pm \mathrm{SD})$ \\
\hline Group 1 & & & & & & \\
\hline Age [years] & 53 & 35.77 & 34.00 & 14.00 & 59.00 & 9.27 \\
\hline Weight [kg] & 53 & 84.90 & 85.00 & 49.00 & 170.00 & 19.53 \\
\hline Height [cm] & 53 & 175.86 & 176.00 & 157.00 & 193.00 & 9.29 \\
\hline BMl [kg/m²] & 53 & 27.31 & 27.50 & 18.90 & 45.60 & 5.13 \\
\hline Group 2 & & & & & & \\
\hline Age [years] & 53 & 48.77 & 49.00 & 14.00 & 77.00 & 14.05 \\
\hline Weight [kg] & 53 & 92.24 & 90.00 & 50.00 & 146.00 & 20.09 \\
\hline Height [cm] & 53 & 178.60 & 180.00 & 159.00 & 197.00 & 7.03 \\
\hline BMl [kg/m²] & 53 & 28.80 & 27.80 & 16.90 & 44.60 & 5.63 \\
\hline
\end{tabular}

\section{RESULTS}

In the evaluation of the level of physical activity, an important element is the sum of all types of physical activity undertaken during the week. The total level of physical activity expressed in MET-min/week, respectively, was in Group 1 - 4532.88 \pm 3611.6 MET-min/week, and was considerably higher, compared to the control group (3142.58 \pm 2536.9 MET-min/week). Also, the value of weekly caloric cost (KAF kcalxweek ${ }^{-1}$ ) showed higher values in Group 1 (6935.77 \pm 5957.4$)$, compared to the control group (4274 \pm 3344.9$)$.

Efforts on an intensive level (MET1) were undertaken with the mean energy expenditure in Group $1-1372.22 \pm 1001.8$ $\mathrm{MET} / \mathrm{min} /$ week, and the mean caloric cost KAF1 $2004.82 \pm 1315.7$ kcalxweek $^{-1}$. In Group $2-704.15 \pm 1001.8$ (MET1); $942.17 \pm 1315.7$ (KAF1). Efforts on the moderate level were undertaken, on average, in Group 1 - (MET2 1372 \pm 1646.6 ; KAF2 2086.67 \pm 2580.3$)$, in Group 2 - MET2 $1539.62 \pm 1899.3$; KAF2 2093.17 \pm 2469.9 . Efforts related with walking/going for a walk was as follows: Groiup 1 - MET3 1788.66 \pm 2160.6 , KAF3 2844.26 \pm 4007.8 , Group 2 MET3 898.81 \pm 2536.9 , KAF3 $1238.65 \pm 1356.03$. The results of the study indicate that despite concomitant diseases, Group 1 showed considerably higher values of undertaking physical activity, especially intensive efforts and walking/going for walks, compared to the control group, which was also reflected by the level of caloric cost of individual physical efforts (Fig. 3).

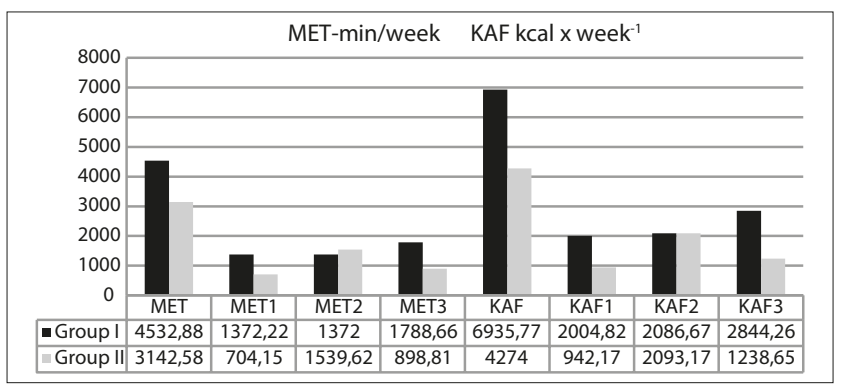

Figure 3. Level of weekly energy expenditure and caloric cost according to the level of physical activity (MET1/KAF1-intensive efforts; MET2/KAF2- moderate; MET3/KAF3-walking)

The results of the study demonstrate that according to the respondents' subjective opinions, the entire group, irrespective of concomitant diseases, may be classified into physical activity on a /high' level ( $\uparrow 1,500-3,000 \mathrm{MET}$-min/week). However, considering the mean number of days and time of undertaking various forms of physical activity, the individual groups did not fall within the standards of this level of activity. The characteristics of a high level is the undertaking of activity for at least 3-7 days, and the sufficient level of 3-5 days. Additionally, it is recommended to undertake physical activity on a moderate level ( $\geq 150 \mathrm{~min} / \mathrm{week})$, or an intensive level ( $\geq 75 \mathrm{~min} /$ week), or the equivalent of a combination of the two types of physical effort. The results of the presented study show considerably higher values of the examined parameters in Group 1, compared to the control group.

The mean value of the days of intensive physical effort and its time (week), respectively, was in Group $1-1.962 \pm 1.9$ days; $65.830 \pm 64.5 \mathrm{~min}$, in Group $2-1.189 \pm 1.3$ days; $45.377 \pm 45.5 \mathrm{~min}$. The mean values of days/time of moderate physical effort was: in Group $1-3.830 \pm 2.3$ days, $87.925 \pm 80.4 \mathrm{~min}$; in Group $2-2.981 \pm 2.1$ days, $101.981 \pm 94.4 \mathrm{~min}$. The time and days devoted to walking was as follows: Group $1-5.887 \pm 1.9$ days; $87.302 \pm 94.0 \mathrm{~min}$, and in Group $2-4.962 \pm 2.3$ days; $47.151 \pm 35.5 \mathrm{~min}$. (Tab. 2). 
Table 2. Evaluation of individual levels of weekly physical activity in the examined groups according to time/days

\begin{tabular}{lcccccc}
\hline \multirow{2}{*}{ Variable } & $\mathrm{N}$ & Mean & Median & $\begin{array}{c}\text { Mini- } \\
\text { mum }\end{array}$ & $\begin{array}{c}\text { Maxi- } \\
\text { mum }\end{array}$ & $\begin{array}{c}\text { St. dev. } \\
( \pm S D)\end{array}$ \\
\cline { 2 - 7 } & \multicolumn{5}{c}{ Group 1 } \\
\hline Intensive efforts (days) & 53 & 1.962 & 1,000 & 0.0000 & 7.00 & 1.9 \\
\hline Intensive efforts (time/min) & 53 & 65.830 & 60,000 & 0.0000 & 300.00 & 64.5 \\
\hline Moderate efforts (days) & 53 & 3.830 & 4,000 & 0.0000 & 7.00 & 2.3 \\
\hline Moderate efforts (time/min.) & 53 & 87.925 & 60,000 & 0.0000 & 390.00 & 80.4 \\
\hline Walking (days) & 53 & 5.887 & 7,000 & 0.0000 & 7.00 & 1.9 \\
\hline Walking (time/min.) & 53 & 87.302 & 60,000 & 0.0000 & 600.00 & 94.0 \\
\hline Sitting (days/time) & 53 & 0.000 & 0,000 & 0.0000 & 0.00 & 0.0 \\
\hline Intensive efforts (days) & 53 & 1.189 & 1,000 & 0.00000 & 5.00 & 1.3 \\
\hline Intensive efforts (time/min.) & 53 & 45.377 & 30,000 & 0.00000 & 180.00 & 45.5 \\
\hline Moderate efforts (days)) & 53 & 2.981 & 3,000 & 0.00000 & 7.00 & 2.1 \\
\hline Moderate efforts (time) & 53 & 101.981 & 60,000 & 0.00000 & 360.00 & 94.4 \\
\hline Walking (days) & 53 & 4.962 & 5,000 & 0.00000 & 7.00 & 2.3 \\
\hline Walking (time/min.) & 53 & 47.151 & 40,000 & 0.00000 & 180.00 & 35.5 \\
\hline Sitting (days/time) & 53 & 0.000 & 0,000 & 0.00000 & 0.00 & 0.0 \\
\hline
\end{tabular}

Considering the inconsistency of the data with normal distribution, Mann-Whitney U Test was applied instead of t-Student test, which showed a statistically significant difference on the level of total weekly energy expenditure (MET) and its caloric cost (KAF), as well as efforts on an intensive level (MET1, KAF1), walking/going for walks (MET3, KAF3), and the actual activity. The test did not show statistically significant differences on the level of moderate activity (MET2), and its caloric cost (KAF2) (Fig.4; Tab.3).

The results of the study demonstrate strong interrelation between weekly energy expenditure (MET-min/week), and its caloric cost (KAF kcal x week ${ }^{-1}$ (Fig. 5).

Statistical analysis showed a statistically significant difference between the declared activity (self-reported) and the actual activity in the examined groups. The declared level of physical activity indicated statistically significant differences with respect to the actual activity (assessment from the application accelerometer) according to the BMI. In Group 1, as many as $77.3 \%$ of patients showed a higher level of declared physical activity, compared to the actual activity; in the control group, this percentage was slightly higher $-75.4 \%$. Considering the BMI, the results of the study demonstrate that in Group 1 the level of own physical activity was overestimated mainly by patients with a high BMI value (overweight-76.1\%; obesity-85\%), while in the control group, these were persons with a normal BMI - 78.9\% (Tab. 4).

Table 4. Evaluation of the level of actual physical activity in the examined group (sign test)

\begin{tabular}{|c|c|c|c|c|c|}
\hline & Sign test $p<0.05$ & & & & \\
\hline & & $\mathrm{N}$ & $\%$ & Z & $\mathrm{p}$ \\
\hline \multirow{3}{*}{$\begin{array}{l}\text { Actual activity\& } \\
\text { declaration of } \\
\text { activity }\end{array}$} & Group 1 & 53 & 77.3 & 3.846096 & 0.000120 \\
\hline & Group 2 & 53 & 75.4 & 3.571375 & 0.000355 \\
\hline & Sign test $p<0.05$ & & & & \\
\hline \multirow{3}{*}{$\begin{array}{l}\text { Actual activity\& } \\
\text { declaration of } \\
\text { activity }\end{array}$} & $\begin{array}{l}\text { Group } 1 \\
\text { Overweight }\end{array}$ & 21 & 76.1 & 2.182179 & 0.029096 \\
\hline & Group 1 Obesity & 20 & 85 & 2.906888 & 0.003650 \\
\hline & $\begin{array}{l}\text { Group } 2 \\
\text { Normal weight }\end{array}$ & 19 & 78.9 & 2.294157 & 0.021781 \\
\hline
\end{tabular}

The results of the study show the presence of a positive correlation between the total energy expenditure (MET) and its caloric cost (KAF), according to the level of physical efforts (MET1, MET2, MET3), and their duration, irrespective of the affiliation to the group (Tab. 5).

Table 5. Correlations of parameters MET, KAF with the level of intensity of physical activity and time of its duration

\begin{tabular}{|c|c|c|c|c|c|c|}
\hline \multicolumn{7}{|l|}{$\begin{array}{l}\text { Spearman } \\
\text { rank } \\
\text { correlation } \\
\text { (random } \\
\text { data) } \\
\mathrm{p}<0.05\end{array}$} \\
\hline Variable & $\begin{array}{l}\text { Intensive } \\
\text { efforts } \\
\text { (days) }\end{array}$ & $\begin{array}{l}\text { Intensive } \\
\text { efforts } \\
\text { (time/ } \\
\text { min.) }\end{array}$ & $\begin{array}{c}\text { Moderate } \\
\text { efforts } \\
\text { (days) }\end{array}$ & $\begin{array}{c}\text { Moderate } \\
\text { efforts } \\
\text { (time/ } \\
\text { min.) }\end{array}$ & $\begin{array}{l}\text { Walking } \\
\text { (days) }\end{array}$ & $\begin{array}{c}\text { Walking } \\
\text { (time/ } \\
\text { min.) }\end{array}$ \\
\hline $\begin{array}{l}\text { MET-min/ } \\
\text { week }\end{array}$ & 0.506 & 0.491 & 0.515 & 0.542 & 0.361 & 0.547 \\
\hline $\begin{array}{l}\text { KAF kcal x } \\
\text { week }^{-1}\end{array}$ & 0.455 & 0.458 & 0.498 & 0.531 & 0.370 & 0.542 \\
\hline
\end{tabular}

Table 3. Evaluation of statistical significance of examined parameters (Mann-Whitney U Test)

\begin{tabular}{|c|c|c|c|c|c|c|c|c|c|c|}
\hline \multicolumn{11}{|c|}{$\begin{array}{l}\text { Mann Whitney U Test } \\
\mathrm{p}<0.05\end{array}$} \\
\hline Variable & Rank sum & Rank sum & $\mathrm{U}$ & Z & $p$ & Z & $p$ & $\mathrm{~N}$ & $\mathrm{~N}$ & $2 * 1$ str \\
\hline MET & 2499.00 & 3172.00 & 1068.00 & -2.12 & 0.033 & -2.12 & 0.033 & 53 & 53 & 0.03 \\
\hline MET1 & 2514.00 & 3157.00 & 1083.00 & -2.02 & 0.042 & -2.07 & 0.037 & 53 & 53 & 0.04 \\
\hline MET3 & 2400.00 & 3271.00 & 969.00 & -2.74 & 0.005 & -2.76 & 0.005 & 53 & 53 & 0.005 \\
\hline Actual activity & 2450.00 & 3221.00 & 1019.00 & -2.43 & 0.014 & -2.43 & 0.014 & 53 & 53 & 0.014 \\
\hline $\mathrm{KAF}$ & 2410.00 & 3261.00 & 979.00 & -2.68 & 0.007 & -2.68 & 0.007 & 53 & 53 & 0.006 \\
\hline KAF1 & 2493.50 & 3177.50 & 1062.50 & -2.15 & 0.030 & -2.20 & 0.027 & 53 & 53 & 0.03 \\
\hline KAF3 & 2330.50 & 3340.50 & 899.50 & -3.18 & 0.001 & -3.18 & 0.001 & 53 & 53 & 0.001 \\
\hline
\end{tabular}




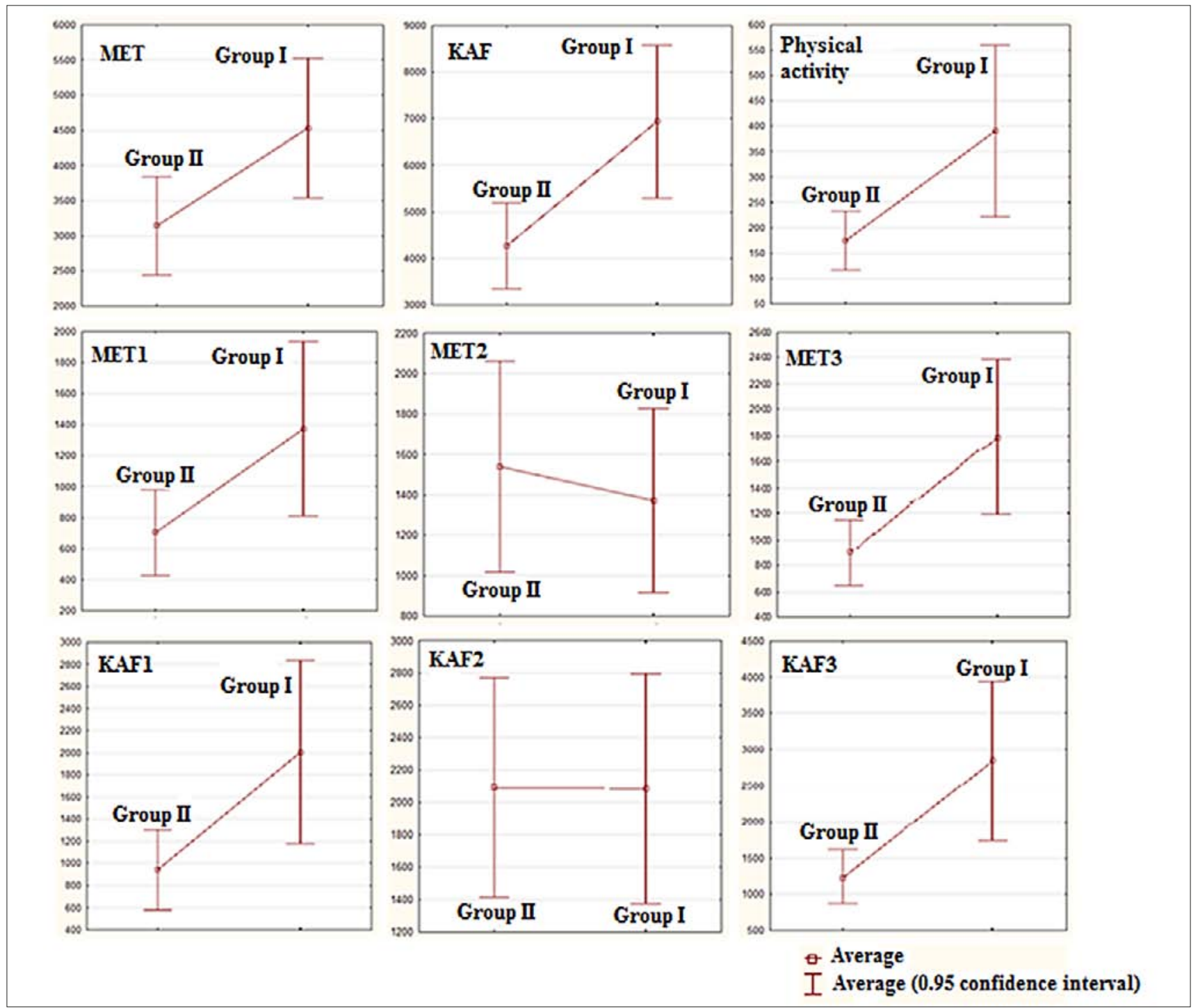

Figure 4. Evaluation of mean values of examined parameters in individual groups

\section{DISCUSSION}

Physical activity is an important element resulting in the reduction of the rate of cardiovascular events [20], and it also exerts a positive effect on the level of cardiac efficiency and quality of life in patients with heart failure and coronary disease $[21,22]$. There are many non-modifiable risk factors of cardiovascular system diseases, for example, male gender [23]. The results of the presented study indicate that the prevalent part of the study group were males, both in Group 1 (92\%) and in Group 2 (74\%).

Statistical analysis assessing the level of physical activity in the examined groups confirmed that patients with concomitant diseases of the cardiovascular system showed a considerably higher level of physical activity, compared to the control group. The total level of weekly physical activity in Group 1 was 4532.88 \pm 3611.6 MET-min/week, and was considerably higher, compared to the control group (3142.58 $\pm 2536.9 \mathrm{MET}-\mathrm{min} /$ week). Also, the values of weekly caloric cost (KAF kcalxweek ${ }^{-1}$ ) showed higher values (6935.77 \pm 5957.4$)$, compared to the control group (4274 \pm 3344.9$)$. The group of cardiologic patients (Group 1) presented a higher level, especially from the aspect of efforts on the intensive level and low level - walking/going for walks (MET1, MET3), which was also translated into the caloric cost of these levels of physical activity (KAF1, KAF3). The results of studies by Wang et al. indicated that one of the factors which may exert an effect on the level of physical activity after a cardiac event is the self-management of the rehabilitation programme in home conditions [24]. In addition, Wolf-May et al. confirmed that a past cardiac event, especially in a group of males, resulted in a considerable change in health behaviours through an increase in physical activity [25], which may also be observed in the difference in undertaking physical activity in the groups examined in the presented study.

The level of physical activity not exceeding 4-5 MET, or not causing expenditure of over $500 \mathrm{kcal}$ during the week, is ascribed to physical activity on an insufficient level. Many researchers define such an activity as physical effort lower than $10 \%$ of the total daily energy expenditure, or of duration not exceeding 25 minutes daily. According to the guidelines, the recommended level of physical activity performed during leisure time should be more than $1,000 \mathrm{kcal} /$ week, which is equivalent to physical activity on a moderate level, until reaching $60-70 \%$ of the maximum rate of contraction of 

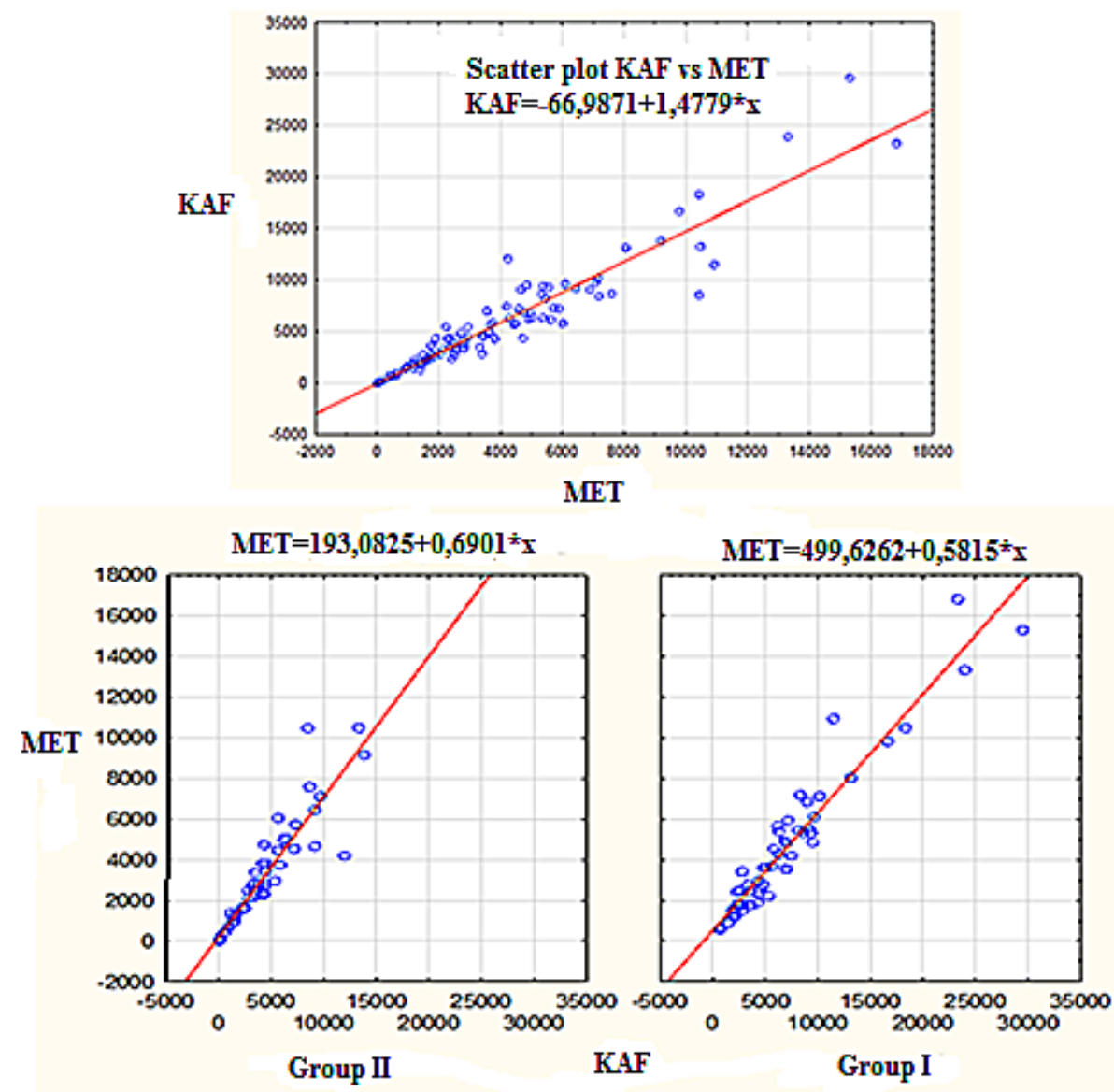

Figure 5. Dispersion of weekly physical activity (MET) and caloric cost (KAF) in the examined group

the cardiac muscle [26]. In own study, the weekly caloric cost of individual levels of activity in individual groups was assessed. Using the assumptions by Paffenbarger et al., for an adult person (70 kg body weight) the minimum energy expenditure should remain within $2,000 \mathrm{kcal} \mathrm{x}^{\mathrm{w}}$ week $^{-1}(300$ $\mathrm{kcal} / \mathrm{day}^{-1}$ ) [27]. The study showed that in Group 1, all levels of physical activity remained within normal values (KAF1 KAF1 2004.82 \pm 1315.7 ; KAF2 2086.67 \pm 2580.3 ; KAF3 $2844.26 \pm 4007.8$ ), while in Group 2 only the efforts on a moderate level were above the normal value (KAF2 KAF2 $2093.17 \pm 2469.9)$. Health organizations worldwide, such as the American Collage of Sport Medicine and the World Health Organization, in order to maintain health and counteract civilisation diseases among adults (aged 18-65), recommend undertaking physical activity on a moderate level (4-6 MET) for not less than 30 minutes daily ( $\geq 150 \mathrm{~min} /$ week), for at least 5 days a week, or intensive efforts ( $>6 \mathrm{MET}), 3$ times a week for at least 20 minutes daily ( $\geq 75 \mathrm{~min} /$ week) $[28,29]$.

The results of the presented study, despite the qualification of the group into the level of high/sufficient activity, do not satisfy the criteria from the aspect of frequency and time of undertaking physical effort. The mean value of the days of intensive effort and its time (week),, respectively, was: in Group $1-1.962 \pm 1.9$ days; $65.830 \pm 64.5 \mathrm{~min}$, and in Group $2-1.189 \pm 1.3$ days; $45.377 \pm 45.5$ min., whereas the values of moderate efforts were: in Group $1-3.830 \pm 2.3$ days, $87.925 \pm 80.4 \mathrm{~min}$; in Group 2 - 2.981 \pm 2.1 days, $101.981 \pm 94.4$ min. However, it should be emphasized that the results of the majority of the examined parameters showed considerably higher values in Group 1, compared to the control group.

The results of studies conducted for many years emphasize that the undertaking of any physical activity is better than its lack, and the higher the level of physical activity, the higher the level of total energy expenditure [30]. This is also confirmed by the results of the presented study which indicate a strong relationship between weekly energy expenditure (MET-min/week) and its caloric cost (KAF kcalx week ${ }^{-1}$ ). In addition, the results show the presence of a positive correlation between total energy expenditure (MET) and its caloric cost (KAF), according to the level of physical efforts (MET1, MET2, MET3) and their duration, irrespective of affiliation to the group.

One of the major problems observed in this study was a considerable overestimation of the level of physical activity self-reported by patients, which was also confirmed by the results of the study by Shephard et al. [31]. In Group 1, as many as $77.3 \%$ of patients declared a higher level of physical activity with respect to the actual activity; in the control group, this percentage was slightly higher $-75.4 \%$. Considering the BMI value, the results of the study showed that in Group 1 own level of physical activity was overestimated mainly by patients with a high BMI (overweight $-76.1 \%$; obesity $-85 \%$ ), while in the control group, those with a normal BMI - 78.9\%.

Physical activity plays an important role in patients who have undergone cardiovascular events, as an instrument of secondary prevention, but primarily as an important factor in counteracting these events, playing a superior role in primary prevention. Therefore, an important role of health 
services is the promotion of physical activity, mainly by the education of patients whose share in the shaping of own health is the greatest.

\section{CONCLUSIONS}

1. The results of the study indicated a statistically significantly higher level of physical activity in the group of patients with concomitant cardiovascular diseases, compared to the control group, which may constitute an important problem in the primary prevention of heart diseases in this group of patients.

2. An important problem also seems to be the overestimation of the level of physical activity in the subjective opinions of patients, especially in the control group.

\section{PROTECTION OF HUMAN SUBJECTS}

The study was performed in compliance with the World Medical Association Declaration of Helsinki on Ethical Principles for Medical Research Involving Human Subjects. The authors requested the opinion of the Ethics Committee at the Institute of Rural Health and obtained consent for the study.

\section{REFERENCES}

1. Noncommunicable diseases. WHO (2014). Regional Office for Europe.

2. Mirat J. Physical activity in the prevention and treatment of cardiovascular diseases. Acta Med Croatia 2007; 61 (suppl.1): 63-67.

3. Warburton DE, Nicol CW, Bredin SS. Health benefits of physical activity: the evidence. CMAJ 2006; 174(6): 801-809.

4. Blair S, Cheng Y, Holder J. Is physical activity or physical fitness more important in defining health benefits? Med Sci Sports Exerc. 2001; 33 (suppl.): 379-399.

5. Taylor RS, Brown A, Ebrahim S, et al. Exercise-based rehabilitation for patients with coronary heart disease: systematic review and metaanalysis of randomized controlled trials. Am J Med. 2004; 116: 682-692.

6. Hambrecht R, Wolf A, Gielen S, Linke A, Hofer J, Erbs S. Effect of exercise on coronary endothelial function in patients with coronary artery disease. N Engl J Med. 2000; 342: 454-460.

7. Sesso HD, Paffenbarger RS Jr, Lee IM. Physical activity and coronary heart disease in men. The Harvard Alumni Health Study. Circulation 2000; 102(9): 975-980.

8. Cheng X, Li W, Guo J, et al. Physical activity levels, sport activities, and risk of acute myocardial infarction: results of the INTERHEART study in China. Angiology 2014; 65(2): 113-121.

9. Smedt DD, Clavs E, Annemans L, et al. The association between selfreported lifestyle changes and health-related quality of life in coronary patients: The EUROASPIRE III survey. Eur J PrevCardiol. 2014; 21(7): 796-805.

10. Yates T, Haffner SM, Schulte PJ, et al. Association between change in daily ambulatory activity and cardiovascular events in people with impaired glucose tolerance (NAVIGATOR trial): A cohort analysis. Lancet 2014; 384(9922): 1059-1066.

11. Wenger NK. Cardiac Rehabilitation: Implications of the AHCPR Guideline. Hosp Med. 1997; 33: 31-38.

12. ExTraMATCH Collaborative. Exercise training meta-analysis of trials in patients with chronic heart failure (ExTraMATCH) Br Med J. 2004; 328: 189-192.

13. Paré G, Sicotte C, St.-Jules D, Gauthier R. Cost-Minimization Analysis of a Telehomecare Program for Patients with Chronic Obstructive Pulmonary Disease. Telemed e-Health 2006; 12(2): 114-121.

14. Keteyian SJ. Exercie Training in Congesive Heart Failure: Risks and Benefits. Progress in Cardiovascular Disease 2011; 53: 419-428.

15. WHO (2010) Global Recommendations on Physical Activity for Health.

16. Bauman A, Bull F, Chey T, Craig CL, Ainsworth BE, Sallis JF, et al. The International Prevalence Study on Physical Activity: results from 20 countries. Int J Behav Nutr Phys Act. 2009; 6: 1-11.

17. Neilson HK, Robson PR, Friedenreich CM, Csizmadi I. Estimating activity energy expenditure: how valid are physical activity questionnaires? Am J Clin Nutr. 2008; 7: 279-291.

18. Mahabir S, Baer DJ, Giffen C, Clevidence B, Campbell WS, Taylor PR. Comparison of energy expenditure estimates from 4 physical activity Questionnaire with doubly labeled water estimates in postmenopausal women. Am J Clin Nutr. 2006; 84(1): 230-236.

19. Pate RR, Prat M, Blair SN, Haskell WL, Macera CA, Bouchardet C, et al. Physical activity and public health. A recommendation from the centers for Disease Control and Prevention and the American College of Sports Medicine. J Am Med Assoc. 1995; 273(5): 402-407.

20. Mora S, Cook N, Buring J. Physical activity and reduced risk of cardiovascular events. Circulation 2007; 116: 2110-2118.

21. Fletcher GF, Balady GJ, Amsterdam EA, et al. Exercise standards for testing and training: A statement for healthcare professionals from the American Heart Association. Circulation 2001; 104: 1694-1740.

22. Szot W, Zając J, Kostkiewicz M, Owoc J, Bojar I. Cardiac rehabilitation: a good measure to improve quality of life in peri- and postmenopausal women with microvascular angina. Ann Agric Environ Med. 2015; 22: 390-395.

23. American Heart Association. Heart Disease and Stroke StatisticsUpdate 2006. Dallas, Texas: American Heart Association 2006.

24. Wang W, Jiang Y, He HG. A randomised controlled trial on the effectiveness of a home-based self-management programme for community-dwelling patients with myocardial infarction. Eur J CardiovascNurs. 2015.

25. Woolf-May K, Bird S, MacIntyre P. Physical activity levels during phase IV cardiac rehabilitation in a group of male myocardial infarction patients. B J Sports Med. 2005; 39(3).

26. European Guidelines on CVD Prevention in Clinical Practice. Eur Heart J. 2003; 24(14): 1601-1610.

27. Paffenbarger RSJr, Hyde RT, Wing AL. Physical activity and physical fitness as determinants of health and longevity. In: Bouchard C, Shephard RJ, Stephens TS, Sutton JR, McPherson BD. [ed.]. Exercise, fitness, and health. Human Kinetics Publishers, Champaign, IL (USA) 1990; pp. 33-48.

28. Haskell WL, Lee I-M, Pate RR, Powell KE, Blair SN, Franklin BA. Physical activity and public health: Updated recommendation for adults from the American College of Sports Medicine and the American Heart Association. Med Sci Sports Exerc. 2007; 39(8): 1423-1434.

29. Global recommendations on Physical activity for Health: World Health Organization, Geneva 2010.

30. Brownell KD, Wadden TA. The learn Program for Weight Control. American Health Publishing Company. Dallas 1999.

31. Shephard RJ. Limits to the measurement of habitu al Physical activity by Questionnaire. Br J Sports Med. 2003; 37: 197-206. 